\title{
ARAS-FUCOM approach for VPAF fighter aircraft selection
}

\author{
Pham Van Hoan ${ }^{\mathrm{a}}$ and Yonghoon $\mathrm{Ha}^{\mathrm{b}^{*}}$
}

${ }^{a}$ Air Defense - Air Force technical institute, Vietnam

${ }^{b}$ Department of Defense Science, Korea National Defense University, South Korea

\begin{tabular}{l}
\hline C H R O N I C L E \\
\hline Article history: \\
Received August 22, 2020 \\
Received in revised format: \\
August 31, 2020 \\
Accepted October 112020 \\
Available online \\
October 11, 2020 \\
\hline Keywords: \\
FUCOM \\
ARAS \\
Fighter aircraft \\
MCDM \\
VPAF
\end{tabular}

\begin{abstract}
A B S T R A C T
Multi-criteria decision making (MCDM) methods are systematical science projects to help decision-makers reach accurate decisions. Applying MCDM methods in the military is important because accurate decision making is the deciding factor for success and can reduce expenditure and increase defense capability. The full consistency method (FUCOM), one of the methods in the MCDM group, has many advantages, and its results are reliable. This paper aims to evaluate and select an appropriate fighter aircraft for Vietnam People's Air Force. Using FUCOM as a decision-making process, we find the final weight values of criteria and apply the additive ratio assessment (ARAS) method to derive the final ranking of alternatives to comply with criteria. Sensitivity analysis is conducted and the result is compared with the weighted product method to substantiate the sturdiness of the proposed method. The results show the Su-35 as the best available solution.
\end{abstract}

\section{Introduction}

Multi-criteria decision making (MCDM) methods are widely employed in several fields such as economics, environment, management, logistics, aviation to help decision-makers reach uncomplicated and accurate decisions. Some popular MCDM methods that are applied include BWM, AHP, Fuzzi, TOPSIS, and DEA. However, in 2018, the Pamučar et al. (2018) proposed a new model to determine the weight of criteria in MCDM models, namely, the full consistency method (FUCOM). Although the steps and pairwise comparison in FUCOM are reduced, it provides more reliable results than other popular methods and has been applied in several fields, such as logistics, environment science, evaluation, and civil aviation. However, the FUCOM method is yet to be used in the military practices; hence, testing whether FUCOM is applicable in military field could help identify its shortcomings. The Vietnam People's Air Force (VPAF), one of the arm forces, plays an essential role in the national defence. However, the lack of new generation fighters adversely impacts the capability of VPAF, necessitating modernisation and upgradation of its fighter aircraft. The final decision making for a fighter aircraft selection must be methodical and systematic analytics to ensure a feasible and appropriate selection is critical for the VPAF.

This paper presents a combined additive ratio assessment (ARAS)-FUCOM approach, which employs scientific systems and supports the fighter aircraft selection in VPAF. Furthermore, this method uses closely proposed construction, and precise analysis to helps decision-making.

\section{Literature Review}

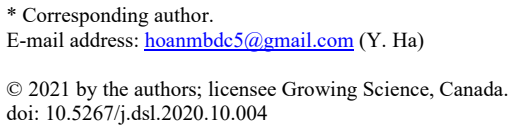


MCDM methods use a varying set of criteria for evaluation and support decision-makers in determining the best choice or alternative with great efficiency. We divide this section into two parts: (1) in the first part, we apply MCDM for aircraft selection problems and (2) in second part, we employ the FUCOM and ARAS approach for evaluation and ranking alternatives.

\subsection{Applying MCDM for aircraft selection problems}

Wang and Chang (2007), Stanujkic et al. (2015), Dožić and Kalić (2016), Paul et al. (2017), and Ali et al. (2017) focused on a set of critical criteria for comparison and applied TOPSIS, AHP method, and another method to analyse the sensitivity of alternative ranking in the same problems and conditions for all types of aircraft. Dožić and Kalić (2015) compared the AHP and ESM method, and conducted responsive analysis in different ways for aircraft selection problem. The results show that the AHP method is sensitive, while ESM is not sensitive to different pairwise comparisons. Kiraci and Bakir (2018) used AHP, COPRAS, and MOORA methods for criteria determination and selection of the best aircraft from among some candidate aircraft. All analyses were based on the price, environment operation, and performance factors.

\subsection{Employing the FUCOM method and ARAS method for evaluation and ranking alternatives}

Pamucar et al. (2018) proposed a new model, FUCOM to determine weight coefficients of criteria. The result shows that the number of pairwise comparisons needed for decision-making was lower (only n -1) than those for the BWM and AHP method and consistent. Fazlollahtabar et al. (2019) applied FUCOM method to derive the weight of criteria values, while WASPAS model was used to rank and estimate forklifts. Sofuoğlu (2020) combined the FUCOM method with fuzzy TOPSIS and fuzzy WASPAS methods to ascertain the most suitable manufacturing method in manufacturing environment. Cao et al. (2019) presented a hybrid method, knows as the Grey SWARA-FUCOM method to select the best solution for the evaluation contractor who install floating solar energy systems. This method expands a decision maker's assurance. Badi and Abdulshahed (2019) employed FUCOM and AHP method to appraise and compare the performance of Libyan Airlines relied on five main performances areas-employees, management, customer's pleasure, airline reliability, and tangibles. Durmić (2019) applied the FUCOM method to evaluate the criteria for sustainable supplier selection. Edmundas and Zenonas (2010) proposed a new ARAS method to evaluate micro-climate in office rooms and show that the ARAS method is expedient to evaluate and rank alternatives. Zavadskas and Turskis (2010) presented a solution to select alternatives in construction by using ARAS method base on price, duration of instalment, maintainability, and transferability with considering client factors and factors influences construction efficiency. Karabasevic et al. (2015) focused on identifying the social indicators and a mentioned framework to evaluate and rank the companies to improve the corporation's image and responsibility using the combined SWARA and ARAS methods. Karabašević et al. (2016) determined some key criteria in human resources and applied SWARA and ARAS methods for the candidate selection in the process of recruitment personnel to meet requirements and achieve business success. To the best of our knowledge, this study is the first time purpose in using ARAS - FUCOM method to overcome some limitations of the other proposed approaches.

\section{Methodology}

MCDM techniques are utilised in complex situations where decision-makers are delegated the task of selection the best option among many alternatives. A new MCDM method likes as FUCOM was developed by Pamu car et al. using two restraint groups to meet the optimal weight values. This was possible base on mathematical transitivity and making pairwise comparisons. Fazlollahtabar et al. (2019), Sofuoğlu (2020), Cao et al. (2019), Badi and Abdulshahed (2019), and Durmić (2019) have been successfully utilised this method.

\subsection{Full Consistency Method (FUCOM)}

According to Dragan Pamǔcar et al., the FUCOM can be presented in three steps to acquire the weight coefficients.

Step 1. The criteria are ranked in the evaluation criteria set $\mathrm{C}=\left\{c_{1} . c_{2} . \ldots . c_{n}\right\}$ relied on the significance of criteria. The ranking starts from important to the least important criteria. Therefore, the weight values are acquired following Eq. (1)

$$
c_{j}(1)>c_{j}(2)>\ldots>c_{j}(k)
$$

where $k$ is the rank of criterion.

Step 2. The ranking criteria are compared, and determining the comparative priority of evaluation criteria following the expression (2):

$$
\Phi=\left(\varphi_{1 / 2}, \varphi_{2} / 3, \ldots, \varphi_{k /(k+1)}\right)
$$


where $\varphi_{k} /_{(k+1)}$ is the consequential priority when the $C_{j}(k)$ criteria compared with the $C_{j}(k+1)$ criteria, and $k=1, \ldots, \mathrm{n}$.

The comparative priority can be defined in two ways:

(a) Base on decision-makers' penchant, they identify comparative priority between observed criteria.

(b) Decision-makers compare and determine the significance criteria in Eq. (1) base on the predefined scale. Because the first ranked criterion is the most important criteria, which will be compared with itself. Therefore, the decision-makers perform only n-1 pairwise comparison.

Step 3. Calculation of the evaluation criteria $\left(\boldsymbol{\omega}_{1} \cdot \boldsymbol{\omega}_{2} \cdot \ldots . \boldsymbol{\omega}_{n}\right)^{T}$ to find the final weight coefficient values. The final weight values should match two conditions:

(1) The ratio of weight coefficient equals with comparative priority in the observed criteria set, that the following condition is satisfied:

$$
\frac{\omega_{k}}{\omega_{(k+1)}}=\varphi_{k /(k+1)}
$$

(2) Besides the condition (3), the final values should match the mathematical transitivity condition as $\varphi_{k /(k+1)} \otimes$ $\varphi_{(k+1) /(k+2)}=\varphi_{k /(k+2)}$. Where $\varphi_{k /(k+1)}=\frac{\omega_{k}}{\omega_{k+1}}$ and $\varphi_{(k+1) /(k+2)}=\frac{\omega_{k+1}}{\omega_{k+2}} \quad$ that means the $\frac{\omega_{k}}{\omega_{(k+1)}} \otimes \frac{\omega_{k+1}}{\omega_{k+2}}=\frac{\omega_{k}}{\omega_{k+2}}$ acquiring. Therefore, the final weight values of evaluation criteria should meet other condition such as the following:

$$
\frac{\omega_{k}}{\omega_{k+2}}=\varphi_{k /(k+1)} \otimes \varphi_{(k+1) /(k+2)}
$$

when $\frac{\omega_{k}}{\omega_{(k+1)}}=\varphi_{k /(k+1)}$ and $\frac{\omega_{k}}{\omega_{k+2}}=\varphi_{k /(k+1)} \otimes \varphi_{(k+1) /(k+2)}$ are satistified, in that manner the deviation from full consistency (DFC) is responded i.e., $\chi=0$. In that way, the values of weight $\left(\omega_{1}, \omega_{2}, \ldots, \omega_{n}\right)^{T}$ are met the condition $\left|\frac{\omega_{j(k)}}{\omega_{j(k+1)}}-\varphi_{k /(k+1)}\right| \leq \chi$, and $\left|\frac{\omega_{k}}{\omega_{k+2}}-\varphi_{k /(k+1)} \otimes \varphi_{(k+1) /(k+2)}\right| \leq \chi$ with minimum values $\chi$, and satisfy the maximum consistency requirement. The final model, which determines the final weight coefficient values of evaluation, can be identified base on the defined sets showing in Eq. (5):

$$
\begin{aligned}
& \min \chi \\
& \text { subject to } \\
& \left|\frac{\omega_{j(k)}}{\omega_{j(k+1)}}-\varphi_{k /(k+1)}\right| \leq \chi, \forall j \\
& \left|\frac{\omega_{k}}{\omega_{k+2}}-\varphi_{k /(k+1)} \otimes \varphi_{(k+1) /(k+2)}\right| \leq \chi, \forall j \\
& \sum_{j=1}^{n} \omega_{j}=1, \forall j \\
& \omega_{j} \geq 0, \forall j .
\end{aligned}
$$

The final values of the evaluation criteria $\left(\omega_{1}, \omega_{2}, \ldots, \omega_{n}\right)^{T}$ and the DFC $(\chi)$ are obtained by solving the model (5).

\subsection{Additive Ratio Assessment (ARAS) method}

Edmundas et al. mentioned a new ARAS method for ranking the limited number of decision alternatives. The utility function value of the viable alternative is directly ratio to a relative effect and weight of principal criteria in the ARAS method, as follows:

The first step, forming decision-making matrix (DMM):

$$
\mathrm{A}=\left[\begin{array}{ccccc}
a_{01} & \ldots & a_{0 j} & \ldots & a_{0 n} \\
\vdots & \ddots & \vdots & \ddots & \vdots \\
a_{i 1} & \ldots & a_{i j} & \ldots & a_{i n} \\
\vdots & \ddots & \vdots & \ddots & \vdots \\
a_{m 1} & \ldots & a_{m j} & \ldots & a_{m n}
\end{array}\right] ; \quad i=\overline{0, m}, j=\overline{1, n}
$$


where $m$ denotes the alternative number, $n$ is the criteria number, $\mathrm{a}_{\mathrm{ij}}$ represents the performance value of the $i$ alternative in terms of the $j$ criterion, and $\mathrm{a}_{0 \mathrm{j}}$ is the optimal value of $j$ criterion.

If the optimum value of $j$ criterion is indefinite, then:

$$
\begin{aligned}
& a_{0 j}=\max _{i} a_{i j} \text { if } \underset{i}{\max } a_{i j} \text { is preferable } \\
& \qquad a_{0 j}=\min _{i} a_{i j}^{*} \text { if } \min _{i} a_{i j}^{*} \text { is preferable }
\end{aligned}
$$

In the second step, normalizing all initial values of the criteria in the DMM, following equation.

$$
\bar{A}=\left[\begin{array}{ccccc}
\bar{a}_{01} & \ldots & \bar{a}_{0 j} & \ldots & \bar{a}_{0 n} \\
\vdots & \ddots & \vdots & \ddots & \vdots \\
\bar{a}_{i 1} & \ldots & \bar{a}_{i j} & \ldots & \bar{a}_{i n} \\
\vdots & \ddots & \vdots & \ddots & \vdots \\
\bar{a}_{m 1} & \ldots & \bar{a}_{m j} & \ldots & \bar{a}_{m n}
\end{array}\right], i=\overline{0, m}, j=\overline{1, n}
$$

For the maximum values of criteria, we normalize as the equation:

$$
\bar{a}_{i j}=\frac{a_{i j}}{\sum_{i=0}^{m} a_{i j}}
$$

For the minimum values of criteria, following 2 procedures to normalize:

$$
a_{i j}=\frac{1}{a_{i j}^{*}} ; \bar{a}_{i j}=\frac{a_{i j}}{\sum_{i=0}^{m} a_{i j}}
$$

When the criteria' dimensionless values are identified, all the criteria are compared. The third step, defining normalizedweighted matrix with weights $0<\mathrm{w}_{\mathrm{j}}<1$ :

$$
\begin{aligned}
& \sum_{j=1}^{n} w_{j}=1 \\
& \widehat{A}=\left[\begin{array}{ccccc}
\hat{a}_{01} & \ldots & \hat{a}_{0 j} & \ldots & \hat{a}_{0 n} \\
\vdots & \ddots & \vdots & \ddots & \vdots \\
\hat{a}_{i 1} & \ldots & \hat{a}_{i j} & \ldots & \hat{a}_{i n} \\
\vdots & \ddots & \vdots & \ddots & \vdots \\
\hat{a}_{m 1} & \ldots & \hat{a}_{m j} & \ldots & \hat{a}_{m n}
\end{array}\right], i=\overline{0, m}, j=\overline{1, n}
\end{aligned}
$$

The calculation of normalized-weighted values for all the criteria are followed:

$$
\hat{a}_{i j}=\bar{a}_{i j} \cdot w_{j} ; i=\overline{0, m}
$$

where $w_{j}$ denotes the important weight, and $a_{i j}$ denotes the normalized rating of $j$ criterion. The continuing step is identifying the optimality function values as the equation below:

$$
K_{i}=\sum_{j=1}^{n} \hat{a}_{i j} ; i=\overline{0, m}
$$

where $K_{i}$ shows the optimality function value of $i$ alternative. If the value of optimality function $K_{i}$ is great, the alternative is more effective. Therefore, the priority of alternatives can be identified based on the value $K_{i}$. However, in some cases, we need to compare the variant (which is analyzed) with the best one $K_{0}$ to find the degree of alternative utility. To calculate the utility degree, using the equation below:

$$
B_{i}=\frac{K_{i}}{K_{0}} ; i=\overline{0, m}
$$

where $B_{i}$ is the utility degree, and the values $B_{i}$ are in the interval $[0,1]$.

\section{Case Study}

The proposed ARAS-FUCOM is employed to a real problem in the VPAF. Our specific aim is to analyse and evaluate possible alternative fighter aircraft solutions and help the decision-makers in terms of the VPAF conditions and 
requirements. Modern weapons equipment can improve the defence capabilities of nations. Therefore, selecting the most apposite weapon, in general, and fighter aircraft, in particular, is vital for the VPAF. However, selecting the most appropriate among the alternatives is hard. To understand the main features that the candidate fighter aircraft should have, the expert team was formed from the team of the Technical Department and some experts from the Department of Science and Technology of Air Defense (Air Force High Command Headquarters), an expert team from the Air Defense (Air Force Technical Institute), lecturers in the Aviation Department of the Air Defense and Air Force Academy, and experts at the Air Force Officer's College, and some expert managers of Air Force Units. The experts were chosen because of their experience (each with more than 15 years) in operating, using, and studying many types of aircraft or in the field of supplier selection and inventions. All criteria to be used in the model were defined by the expert team based on their experience, the demand of the VPAF, and a literature review. The presentation performed is based on the previous section's steps and explained systematically together with the results. A set of 13 criteria established by the expert team by answering the questionnaire were used for fighter aircraft selection. The selection of alternative aircraft was considered and the decisionmaking team determined three suitable fighter aircraft for the needs, namely, Su-35, Mig-35, and F-16 after determining the criteria.

\subsection{Aircraft evaluation criteria and definition}

From the expert opinions and literature review, a set of thirteen main criteria are namely: The aerodynamic characteristic (C1), The maximum takeoff weight (MTOW) (C2), Armament (C3), Avionics (C4), Power engine (C5), Maximum speed (C6), Service ceiling (C7), Climbing rate (C8), Combat radius (C9), The acquisition cost (C10), The operation cost (C11), Reliability (C12), Strategic cooperation (C13).

Aircraft Evaluation Criteria and Definition

\begin{tabular}{|c|c|c|}
\hline & Criteria & Definition \\
\hline 1 & $\begin{array}{l}\text { The aerodynamic characteristic } \\
\text { (C1) }\end{array}$ & Design aircraft which influents to maneuverability of aircraft showing by wing loading. \\
\hline 2 & The maximum takeoff weight & Allowing aircraft to take off with a maximum weight because of structure features or other limits. \\
\hline 3 & Armament (C3) & The weapons can be used and total weapon weight can carry. \\
\hline 4 & Avionics (C4) & $\begin{array}{l}\text { Radar systems can be programmed to simulate radar contacts, and number targets can be detected. And } \\
\text { electronic systems are indicating and controlling which are setting on aircraft. }\end{array}$ \\
\hline 5 & Power engine (C5) & $\begin{array}{l}\text { To create the propulsive force, when airflow through the engines, which are compressed with high pressure } \\
\text { to increase momentum, and generates the propulsive force directly. }\end{array}$ \\
\hline 6 & Maximum speed (C6) & The maximum operating speed of aircraft showing by Mach number. \\
\hline 7 & Service ceiling $(\mathrm{C} 7)$ & The aircraft can work well and bear the atmosphere at the highest altitude. \\
\hline 8 & Climbing rate $(\mathrm{C} 8)$ & The capability of the aircraft to increase or decrease the altitude in a short time to to enable cruising. \\
\hline 9 & Combat radius (C9) & The maximum distance an aircraft can fly between takeoff and landing. \\
\hline 10 & The acquisition cost (C10) & The final price of an aircraft including legal costs, transport, and discounts. \\
\hline 11 & The operation cost (C11) & All costs occur when flights are actually operated including fuel consumption and maintenance costs, etc. \\
\hline 12 & Reliability (C12) & $\begin{array}{l}\text { The capabilities of aircraft work well under the specified condition without failure of all components in a } \\
\text { specified period of time. }\end{array}$ \\
\hline 13 & Strategic cooperation $(\mathrm{C} 13)$ & Two or more companies or organizations can help each other and cooperate easier to satisfy their aim. \\
\hline
\end{tabular}

The questionnaires were designed to acquire the degree in which criteria are raked base on its significance. A nine-point scale was applied where weakly significance is represented as 9 , equally significance is represented as 7 , essentially significance as 5 , very strongly significance as 3 , absolutely significance as 1 , and the halfway value between two close penchant are $2,4,6$, and 8 .

\subsection{Calculation of the weights of main criteria using FUCOM method}

Step 1. The experts ranked the main criteria. The results are illustrated in Table 1.

Table 1

The summary of the ranking of the main criteria

\begin{tabular}{|c|c|c|c|c|c|c|c|c|c|c|c|c|c|c|c|}
\hline \multirow[t]{2}{*}{ Criteria } & \multicolumn{15}{|c|}{ Ranking } \\
\hline & DM1 & DM2 & DM3 & DM4 & DM5 & DM6 & DM7 & DM8 & DM9 & DM10 & DM11 & DM12 & DM13 & DM14 & DM15 \\
\hline$C_{1}$ & 5 & 8 & 4 & 4 & 1 & 6 & 8 & 8 & 4 & 4 & 4 & 2 & 1 & 6 & 5 \\
\hline$C_{2}$ & 4 & 10 & 9 & 5 & 6 & 3 & 13 & 4 & 10 & 6 & 10 & 9 & 5 & 7 & 7 \\
\hline$C_{3}$ & 7 & 1 & 6 & 1 & 7 & 1 & 1 & 2 & 1 & 2 & 1 & 3 & 2 & 3 & 3 \\
\hline$C_{4}$ & 6 & 2 & 5 & 2 & 9 & 2 & 2 & 3 & 2 & 1 & 2 & 4 & 3 & 4 & 2 \\
\hline$C_{5}$ & 9 & 7 & 7 & 10 & 2 & 5 & 12 & 12 & 5 & 3 & 3 & 5 & 4 & 2 & 1 \\
\hline$C_{6}$ & 2 & 5 & 11 & 3 & 3 & 12 & 9 & 5 & 6 & 5 & 6 & 7 & 6 & 5 & 6 \\
\hline$C_{7}$ & 8 & 4 & 13 & 7 & 4 & 13 & 11 & 10 & 11 & 13 & 12 & 11 & 11 & 13 & 13 \\
\hline$C_{8}$ & 10 & 11 & 12 & 8 & 5 & 11 & 10 & 9 & 7 & 11 & 7 & 8 & 7 & 8 & 8 \\
\hline$C_{9}$ & 3 & 6 & 8 & 6 & 8 & 10 & 3 & 11 & 13 & 12 & 8 & 10 & 8 & 9 & 10 \\
\hline$C_{10}$ & 1 & 3 & 1 & 12 & 11 & 7 & 4 & 1 & 3 & 7 & 5 & 1 & 9 & 1 & 4 \\
\hline$C_{11}$ & 11 & 9 & 2 & 11 & 12 & 8 & 5 & 6 & 8 & 8 & 13 & 13 & 13 & 11 & 11 \\
\hline
\end{tabular}




$\begin{array}{rrrrrrrrrrrrrrrr}C_{12} & 13 & 12 & 3 & 9 & 10 & 4 & 6 & 7 & 9 & 9 & 9 & 6 & 10 & 10 & 9 \\ C_{13} & 12 & 13 & 10 & 13 & 13 & 9 & 7 & 13 & 12 & 10 & 11 & 12 & 12 & 12 & 12\end{array}$

Step 2. The decision-makers performed the pairwise comparison from the first step. Therefore, we have the precedence of the criteria $\left(\varpi_{C_{j(k)}}\right)$ shown in Table 2.

Table 2

Precedence of criteria

\begin{tabular}{|c|c|c|c|c|c|c|c|c|c|c|c|c|c|c|c|}
\hline \multirow[t]{2}{*}{ Criteria } & \multicolumn{15}{|c|}{$\varpi_{C_{i(k)}}$} \\
\hline & DM1 & DM2 & DM3 & DM4 & DM5 & DM6 & DM7 & DM8 & DM9 & DM10 & DM11 & DM12 & DM13 & DM14 & DM15 \\
\hline$C_{1}$ & 4 & 6 & 5 & 3 & 1 & 5 & 7 & 6 & 2 & 2 & 2 & 1 & 1 & 3 & 3 \\
\hline$C_{2}$ & 3 & 6 & 7 & 3 & 3 & 2 & 9 & 2 & 7 & 3 & 6 & 7 & 3 & 4 & 5 \\
\hline$C_{3}$ & 5 & 1 & 5 & 1 & 4 & 1 & 1 & 2 & 1 & 1 & 1 & 2 & 2 & 2 & 1 \\
\hline$C_{4}$ & 5 & 1 & 5 & 1 & 6 & 1 & 1 & 2 & 1 & 1 & 1 & 2 & 2 & 2 & 1 \\
\hline$C_{5}$ & 6 & 5 & 6 & 7 & 2 & 4 & 8 & 7 & 3 & 2 & 2 & 3 & 2 & 2 & 1 \\
\hline$C_{6}$ & 3 & 3 & 8 & 2 & 2 & 7 & 7 & 3 & 5 & 3 & 3 & 5 & 3 & 3 & 5 \\
\hline$C_{7}$ & 5 & 3 & 9 & 5 & 2 & 9 & 8 & 7 & 8 & 9 & 9 & 7 & 6 & 9 & 9 \\
\hline$C_{8}$ & 6 & 7 & 8 & 5 & 3 & 7 & 8 & 6 & 6 & 7 & 5 & 5 & 4 & 5 & 6 \\
\hline$C_{9}$ & 3 & 4 & 7 & 3 & 5 & 6 & 3 & 7 & 9 & 7 & 5 & 7 & 5 & 5 & 7 \\
\hline$C_{10}$ & 1 & 2 & 2 & 8 & 7 & 5 & 3 & 1 & 2 & 4 & 3 & 1 & 5 & 1 & 3 \\
\hline$C_{11}$ & 7 & 6 & 3 & 7 & 8 & 5 & 5 & 5 & 7 & 5 & 9 & 9 & 9 & 7 & 7 \\
\hline$C_{12}$ & 9 & 9 & 3 & 6 & 7 & 3 & 6 & 5 & 7 & 5 & 6 & 4 & 6 & 7 & 6 \\
\hline$C_{13}$ & 8 & 9 & 7 & 9 & 9 & 6 & 6 & 9 & 8 & 6 & 7 & 8 & 7 & 7 & 8 \\
\hline
\end{tabular}

From the acquired priorities of the criteria, the comparative precedence of the criteria are calculated: $\varphi_{c 10 / c 6}=3 / 1=3$; $\varphi_{c 6 / c 9}=3 / 3=1 ; \varphi_{c 9 / c 2}=3 / 3=1 ; \varphi_{c 2 / c 1}=4 / 3=1.33 ; \varphi_{c 1 / c 4}=5 / 4=1.25 ; \varphi_{c 4 / c 3}=5 / 5=1 ; \varphi_{c 3 / c 7}=5 / 5=$ $1 ; \varphi_{c 7 / c 5}=6 / 5=1.2 ; \varphi_{c 5 / c 8}=6 / 6=1 ; \varphi_{c 8 / c 11}=7 / 6=1.17 ; \varphi_{c 11 / c 13}=8 / 7=1.14 ; \varphi_{c 13 / c 12}=9 / 8=1.12$.

Step 3. The final weight coefficient values should satisfy the following two conditions:

a. The final weight coefficient values should match the condition $(3)$, that is: $w_{10} / w_{6}=3 ; w_{6} / w_{9}=1 ; w_{9} / w_{2}=1$; $w_{2} / w_{1}=1.33 ; w_{1} / w_{4}=1.25 ; w_{4} / w_{3}=1 ; w_{3} / w_{7}=1 ; w_{7} / w_{5}=1.2 ; w_{5} / w_{8}=1 ; w_{8} / w_{11}=1.17 ; w_{11} / w_{13}=1.14 ;$ $w_{13} / w_{12}=1.12$

b. The final values of the weight coefficients should meet the condition of mathematical transitivity, beside condition 3 , that is: $w_{10} / w_{9}=3 \times 1=3 ; w_{6} / w_{2}=1 \times 1=1 ; w_{9} / w_{1}=1 \times 1.33=1.33 ; w_{2} / w_{4}=1.33 \times 1.25=1.67 ; w_{1} / w_{3}=$ $1.25 \times 1=1.25 ; w_{4} / w_{7}=1 \times 1=1 ; w_{3} / w_{5}=1 \times 1.2=1.2 ; w_{7} / w_{8}=1.2 \times 1=1.2 ; w_{5} / w_{11}=1 \times 1.17=$ $1.17 ; w_{8} / w_{13}=1.17 \times 1.14=1.33 ; w_{11} / w_{12}=1.14 \times 1.12=1.28$.

Table 3

\begin{tabular}{|c|c|c|c|c|c|c|c|c|c|c|c|c|c|}
\hline \multicolumn{2}{|c|}{ DM1 } & \multicolumn{2}{|c|}{ DM2 } & \multicolumn{2}{|c|}{ DM3 } & \multicolumn{2}{|c|}{ DM4 } & \multicolumn{2}{|c|}{ DM5 } & \multicolumn{2}{|c|}{ DM6 } & \multicolumn{2}{|c|}{ DM7 } \\
\hline$\varphi_{k /(k+1)}$ & $\varphi_{k /(k+2)}$ & $\varphi_{k /(k+1)}$ & $\varphi_{k /(k+2)}$ & $\varphi_{k /(k+1)}$ & $\varphi_{k /(k+2)}$ & $\varphi_{k /(k+1)}$ & $\varphi_{k /(k+2)}$ & $\varphi_{k /(k+1)}$ & $\varphi_{k /(k+2)}$ & $\varphi_{k /(k+1)}$ & $\varphi_{k /(k+2)}$ & $\varphi_{k /(k+1)}$ & $\varphi_{k /(k+2)}$ \\
\hline 3 & 3 & 1 & 2 & 1.5 & 1.5 & 1 & 2 & 2 & 2 & 1 & 2 & 1 & 3 \\
\hline 1 & 1 & 2 & 3 & 1 & 1.67 & 2 & 3 & 1 & 1 & 2 & 3 & 3 & 3 \\
\hline 1 & 1.33 & 1.5 & 1.5 & 1.67 & 1.67 & 1.5 & 1.5 & 1 & 1.5 & 1.5 & 2 & 1 & 1.67 \\
\hline 1.33 & 1.67 & 1 & 1.33 & 1 & 1 & 1 & 1 & 1.5 & 1.5 & 1.33 & 1.67 & 1.67 & 2 \\
\hline 1.25 & 1.25 & 1.33 & 1.67 & 1 & 1.2 & 1 & 1.67 & 1 & 1.33 & 1.25 & 1.25 & 1.2 & 1.2 \\
\hline 1 & 1 & 1.25 & 1.5 & 1.2 & 1.4 & 1.67 & 1.67 & 1.33 & 1.67 & 1 & 1 & 1 & 1.17 \\
\hline 1 & 1.2 & 1.2 & 1.2 & 1.17 & 1.17 & 1 & 1.2 & 1.25 & 1.5 & 1 & 1.2 & 1.17 & 1.16 \\
\hline 1.2 & 1.2 & 1 & 1 & 1 & 1 & 1.2 & 1.4 & 1.2 & 1.4 & 1.2 & 1.2 & 1 & 1.14 \\
\hline 1 & 1.17 & 1 & 1.17 & 1 & 1.14 & 1.17 & 1.17 & 1.17 & 1.17 & 1 & 1.17 & 1.14 & 1.14 \\
\hline 1.17 & 1.33 & 1.17 & 1.5 & 1.14 & 1.14 & 1 & 1.14 & 1 & 1.14 & 1.17 & 1.17 & 1 & 1 \\
\hline 1.14 & 1.28 & 1.28 & 1.28 & 1 & 1.13 & 1.14 & 1.28 & 1.14 & 1.28 & 1 & 1.28 & 1 & 1.12 \\
\hline 1.12 & & 1 & & 1.13 & & 1.13 & & 1.13 & & 1.28 & & 1.12 & \\
\hline
\end{tabular}

Table 4

The results of $\varphi_{k /(k+1)}$ and $\varphi_{k /(k+2)}$

\begin{tabular}{|c|c|c|c|c|c|c|c|c|c|c|c|c|c|c|c|}
\hline \multicolumn{2}{|c|}{ DM8 } & \multicolumn{2}{|c|}{ DM9 } & \multicolumn{2}{|c|}{ DM10 } & \multicolumn{2}{|c|}{ DM11 } & \multicolumn{2}{|c|}{ DM12 } & \multicolumn{2}{|c|}{ DM13 } & \multicolumn{2}{|c|}{ DM14 } & \multicolumn{2}{|c|}{ DM15 } \\
\hline$\varphi_{k /(k+1)}$ & $\varphi_{k /(k+2)}$ & $\varphi_{k /(k+1)}$ & $\varphi_{k /(k+2)}$ & $\varphi_{k /(k+1)}$ & $\varphi_{k /(k+2)}$ & $\varphi_{k /(k+1)}$ & $\varphi_{k /(k+2)}$ & $\varphi_{k /(k+1)}$ & $\varphi_{k /(k+2)}$ & $\varphi_{k /(k+1)}$ & $\varphi_{k /(k+2)}$ & $\varphi_{k /(k+1)}$ & $\varphi_{k /(k+2)}$ & $\varphi_{k /(k+1)}$ & $\varphi_{k /(k+2)}$ \\
\hline 1 & 2 & 1 & 2 & 1 & 2 & 1 & 2 & 1 & 2 & 2 & 2 & 2 & 2 & 1 & 1 \\
\hline 2 & 2 & 2 & 2 & 2 & 2 & 2 & 2 & 2 & 2 & 1 & 1 & 1 & 1 & 1 & 3 \\
\hline 1 & 1.5 & 1 & 1.5 & 1 & 1.5 & 1 & 1.5 & 1 & 1.5 & 1 & 1.5 & 1 & 1.5 & 3 & 3 \\
\hline 1.5 & 2.5 & 1.5 & 2.5 & 1.5 & 1.5 & 1.5 & 1.5 & 1.5 & 2 & 1.5 & 1.5 & 1.5 & 1.5 & 1 & 1.67 \\
\hline 1.67 & 1.67 & 1.67 & 2 & 1 & 1.33 & 1 & 1.67 & 1.33 & 1.67 & 1 & 1.33 & 1 & 1.33 & 1.67 & 1.67 \\
\hline 1 & 1.2 & 1.2 & 1.4 & 1.33 & 1.67 & 1.67 & 1.67 & 1.25 & 1.25 & 1.33 & 1.25 & 1.33 & 1.67 & 1 & 1.2 \\
\hline 1.2 & 1.2 & 1.17 & 1.17 & 1.25 & 1.25 & 1 & 1.2 & 1 & 1.4 & 1.25 & 1.25 & 1.25 & 1.25 & 1.2 & 1.2 \\
\hline 1 & 1.17 & 1 & 1 & 1 & 1.2 & 1.2 & 1.2 & 1.4 & 1.4 & 1 & 1.2 & 1 & 1.4 & 1 & 1.17 \\
\hline 1.17 & 1.17 & 1 & 1.14 & 1.2 & 1.4 & 1 & 1.17 & 1 & 1 & 1.2 & 1.2 & 1.4 & 1.4 & 1.17 & 1.17 \\
\hline 1 & 1 & 1.14 & 1.14 & 1.17 & 1.17 & 1.17 & 1.5 & 1 & 1.14 & 1 & 1.17 & 1 & 1 & 1 & 1.14 \\
\hline
\end{tabular}




\begin{tabular}{|c|c|c|c|c|c|c|c|c|c|c|c|c|c|c|c|}
\hline 1 & 1.28 & 1 & 1.12 & 1 & 1.28 & 1.28 & 1.28 & 1.14 & 1.28 & 1.17 & 1.5 & 1 & 1.28 & 1.14 & 1.28 \\
\hline 1.28 & & 1.12 & & 1.28 & & 1 & & 1.12 & & 1.28 & & 1.28 & & 1.12 & \\
\hline
\end{tabular}

The final model to determine the weight coefficients can be defined by applying the expression (5) as:

$\min \chi$

subject to

$$
\begin{gathered}
\left|\frac{\omega_{10}}{\omega_{6}}-3\right| \leq \chi,\left|\frac{w_{6}}{w_{9}}-1\right| \leq \chi,\left|\frac{w_{9}}{w_{2}}-1\right| \leq \chi,\left|\frac{w_{2}}{w_{1}}-1.33\right| \leq \chi,\left|\frac{w_{1}}{w_{4}}-1.25\right| \leq \chi,\left|\frac{w_{4}}{w_{3}}-1\right| \leq \chi,\left|\frac{w_{3}}{w_{7}}-1\right| \leq \chi, \mid \frac{w_{7}}{w_{5}}- \\
1.2|\leq \chi,| \frac{w_{5}}{w_{8}}-1|\leq \chi,| \frac{w_{8}}{w_{11}}-1.17|\leq \chi,| \frac{w_{11}}{w_{13}}-1.14|\leq \chi,| \frac{w_{13}}{w_{12}}-1.12 \mid \leq \chi, \forall j, \\
\left|\frac{\omega_{10}}{\omega_{9}}-3\right| \leq \chi \cdot\left|\frac{w_{9}}{w_{1}}-1,33\right| \leq \chi \cdot\left|\frac{w_{2}}{w_{4}}-1,67\right| \leq \chi \cdot\left|\frac{w_{1}}{w_{3}}-1,25\right| \leq \chi \cdot\left|\frac{w_{4}}{w_{7}}-1\right| \leq \chi \cdot\left|\frac{w_{3}}{w_{5}}-1,2\right| \leq \chi \cdot \mid \frac{w_{7}}{w_{8}} \\
-1,2|\leq \chi \cdot| \frac{w_{5}}{w_{11}}-1,17|\leq \chi \cdot| \frac{w_{8}}{w_{13}}-1,33|\leq \chi \cdot| \frac{w_{11}}{w_{12}}-1,28 \mid \leq \chi \cdot \forall j .
\end{gathered}
$$$$
\sum_{j=1}^{13} \omega_{j}=1, \forall j
$$

$\omega_{j} \geq 0, \forall j$.

This proposed model is solved by using Lingo software, the final weight coefficient values $\left(\omega_{1}, \omega_{2}, \ldots, \omega_{n}\right)^{T}$ are presented in Table 5.

Table 5

The final values of weight coefficients

\begin{tabular}{lccccccccccccccccc}
\hline & $C_{1}$ & $C_{2}$ & $C_{3}$ & $C_{4}$ & $C_{5}$ & $C_{6}$ & $C_{7}$ & $C_{8}$ & $C_{9}$ & $C_{10}$ & $C_{11}$ \\
\hline DM1 & 0.258 & 0.346 & 0.233 & 0.208 & 0.176 & 0.346 & 0.21 & 0.176 & 0.346 & 0.281 & 0.15 & 0.092 & 0.105 \\
DM2 & 0.268 & 0.119 & 0.111 & 0.111 & 0.408 & 0.168 & 0.054 & 0.272 & 0.239 & 0.15 & 0.268 & 0.489 & 0.217 \\
DM3 & 0.27 & 0.192 & 0.27 & 0.27 & 0.27 & 0.169 & 0.15 & 0.17 & 0.193 & 0.184 & 0.122 & 0.122 & 0.193 \\
DM4 & 0.307 & 0.123 & 0.115 & 0.115 & 0.152 & 0.092 & 0.133 & 0.099 & 0.091 & 0.106 & 0.192 & 0.297 & 0.362 \\
DM5 & 0.173 & 0.281 & 0.255 & 0.199 & 0.359 & 0.359 & 0.359 & 0.218 & 0.195 & 0.211 & 0.18 & 0.164 & 0.198 \\
DM6 & 0.124 & 0.108 & 0.181 & 0.155 & 0.171 & 0.254 & 0.268 & 0.254 & 0.214 & 0.186 & 0.186 & 0.171 & 0.214 \\
DM7 & 0.131 & 0.101 & 0.252 & 0.252 & 0.115 & 0.131 & 0.114 & 0.114 & 0.309 & 0.309 & 0.185 & 0.154 & 0.154 \\
DM8 & 0.133 & 0.108 & 0.217 & 0.108 & 0.114 & 0.264 & 0.114 & 0.132 & 0.114 & 0.217 & 0.159 & 0.159 & 0.089 \\
DM9 & 0.111 & 0.117 & 0.222 & 0.222 & 0.273 & 0.164 & 0.102 & 0.137 & 0.091 & 0.111 & 0.117 & 0.117 & 0.102 \\
DM10 & 0.103 & 0.25 & 0.206 & 0.206 & 0.103 & 0.25 & 0.082 & 0.106 & 0.106 & 0.187 & 0.15 & 0.15 & 0.125 \\
DM11 & 0.105 & 0.128 & 0.21 & 0.21 & 0.105 & 0.257 & 0.085 & 0.154 & 0.154 & 0.257 & 0.085 & 0.128 & 0.11 \\
DM12 & 0.215 & 0.113 & 0.107 & 0.107 & 0.263 & 0.158 & 0.112 & 0.158 & 0.113 & 0.215 & 0.087 & 0.198 & 0.098 \\
DM13 & 0.125 & 0.235 & 0.275 & 0.275 & 0.275 & 0.235 & 0.298 & 0.235 & 0.256 & 0.256 & 0.24 & 0.294 & 0.35 \\
DM14 & 0.292 & 0.241 & 0.109 & 0.109 & 0.109 & 0.292 & 0.1 & 0.188 & 0.213 & 0.205 & 0.14 & 0.124 & 0.125 \\
DM15 & 0.256 & 0.168 & 0.198 & 0.198 & 0.169 & 0.168 & 0.096 & 0.156 & 0.121 & 0.256 & 0.121 & 0.159 & 0.094 \\
\hline
\end{tabular}

The values of weight coefficients for each decision maker and values procured by employing a geometric mean are illustrated in Table 6.

\begin{tabular}{|c|c|c|c|c|c|c|c|c|c|c|c|c|c|c|c|c|}
\hline Criteria & DM1 & DM2 & DM3 & DM4 & DM5 & DM6 & DM7 & DM8 & DM9 & DM10 & DM11 & DM12 & DM13 & DM14 & DM15 & Mean \\
\hline$C_{1}$ & 0.258 & 0.268 & 0.27 & 0.307 & 0.173 & 0.124 & 0.131 & 0.133 & 0.111 & 0.103 & 0.105 & 0.215 & 0.125 & 0.292 & 0.256 & 0.191 \\
\hline$C_{2}$ & 0.346 & 0.119 & 0.192 & 0.123 & 0.281 & 0.108 & 0.101 & 0.108 & 0.117 & 0.25 & 0.128 & 0.113 & 0.235 & 0.241 & 0.168 & 0.175 \\
\hline$C_{3}$ & 0.233 & 0.111 & 0.27 & 0.115 & 0.255 & 0.181 & 0.252 & 0.217 & 0.222 & 0.206 & 0.21 & 0.107 & 0.275 & 0.109 & 0.198 & 0.197 \\
\hline$C_{4}$ & 0.208 & 0.111 & 0.27 & 0.115 & 0.199 & 0.155 & 0.252 & 0.108 & 0.222 & 0.206 & 0.21 & 0.107 & 0.275 & 0.109 & 0.198 & 0.183 \\
\hline$C_{5}$ & 0.176 & 0.408 & 0.27 & 0.152 & 0.359 & 0.171 & 0.115 & 0.114 & 0.273 & 0.103 & 0.105 & 0.263 & 0.275 & 0.109 & 0.169 & 0.204 \\
\hline$C_{6}$ & 0.346 & 0.168 & 0.169 & 0.092 & 0.359 & 0.254 & 0.131 & 0.264 & 0.164 & 0.25 & 0.257 & 0.158 & 0.235 & 0.292 & 0.168 & 0.221 \\
\hline$C_{7}$ & 0.21 & 0.054 & 0.15 & 0.133 & 0.359 & 0.268 & 0.114 & 0.114 & 0.102 & 0.082 & 0.085 & 0.112 & 0.298 & 0.1 & 0.096 & 0.152 \\
\hline$C_{8}$ & 0.176 & 0.272 & 0.17 & 0.099 & 0.218 & 0.254 & 0.114 & 0.132 & 0.137 & 0.106 & 0.154 & 0.158 & 0.235 & 0.188 & 0.156 & 0.171 \\
\hline$C_{9}$ & 0.346 & 0.239 & 0.193 & 0.091 & 0.195 & 0.214 & 0.309 & 0.114 & 0.091 & 0.106 & 0.154 & 0.113 & 0.256 & 0.213 & 0.121 & 0.184 \\
\hline$C_{10}$ & 0.281 & 0.15 & 0.184 & 0.106 & 0.211 & 0.186 & 0.309 & 0.217 & 0.111 & 0.187 & 0.257 & 0.215 & 0.256 & 0.205 & 0.256 & 0.209 \\
\hline$C_{11}$ & 0.15 & 0.268 & 0.122 & 0.192 & 0.18 & 0.186 & 0.185 & 0.159 & 0.117 & 0.15 & 0.085 & 0.087 & 0.24 & 0.14 & 0.121 & 0.159 \\
\hline$C_{12}$ & 0.092 & 0.489 & 0.122 & 0.297 & 0.164 & 0.171 & 0.154 & 0.159 & 0.117 & 0.15 & 0.128 & 0.198 & 0.294 & 0.124 & 0.159 & 0.188 \\
\hline$C_{13}$ & 0.105 & 0.217 & 0.193 & 0.362 & 0.198 & 0.214 & 0.154 & 0.089 & 0.102 & 0.125 & 0.11 & 0.098 & 0.35 & 0.125 & 0.094 & 0.169 \\
\hline
\end{tabular}

Table 6

The values of weight coefficients acquired by applying a geometric mean 
Following the identification of the criteria, the selection of alternative aircraft were considered and the decision-maker team determined three suitable fighter aircraft for the VPAF, namely, the F-16, Su-35, and Mig-35.

Table 7

Initial decision making matrix

\begin{tabular}{|c|c|c|c|c|c|c|c|c|c|c|c|c|c|}
\hline Alternative & $\mathrm{C} 1$ & $\mathrm{C} 2$ & $\mathrm{C} 3$ & $\mathrm{C} 4$ & $\mathrm{C} 5$ & C6 & $\mathrm{C} 7$ & $\mathrm{C} 8$ & C9 & $\mathrm{C} 10$ & $\mathrm{C} 11$ & C12 & $\mathrm{C} 13$ \\
\hline & $\min$ & $\max$ & $\max$ & $\min$ & $\min$ & $\max$ & $\max$ & $\min$ & $\max$ & $\min$ & $\min$ & $\max$ & $\min$ \\
\hline Ao & 408 & 34500 & 8000 & 200 & 53 & 2.25 & 17.5 & 254 & 3500 & 40 & 8000 & 100 & 5 \\
\hline F-16 & 431 & 16875 & 7700 & 296 & 64.5 & 2.05 & 15.3 & 254 & 3200 & 64 & 8000 & 85.6 & 5 \\
\hline Su-35 & 408 & 34500 & 8000 & 350 & 74.5 & 2.25 & 17.3 & 280 & 3000 & 84 & 28000 & 100 & 7 \\
\hline Mig-35 & 452 & 29700 & 7000 & 200 & 53 & 2.2 & 17.5 & 300 & 3500 & 40 & 28003 & 100 & 7 \\
\hline
\end{tabular}

\section{Step1. Normalized decision matrix}

The normalized decision matrix is created using the following by equation:

$a_{i j}^{*}=\frac{a_{i j}}{\sum_{i=0}^{m} a_{i j}} ; j=1, \ldots, n$

Table 8

The normalized decision matrix

\begin{tabular}{cccccccccccccccc}
\hline Alternative & $\bar{C}_{1}$ & $\bar{C}_{2}$ & $\bar{C}_{3}$ & $\bar{C}_{4}$ & $\bar{C}_{5}$ & $\bar{C}_{6}$ & $\bar{C}_{7}$ & $\bar{C}_{8}$ & $\bar{C}_{9}$ & $\bar{C}_{10}$ & $\bar{C}_{11}$ & $\bar{C}_{12}$ & $\bar{C}_{13}$ \\
\hline Ao & 0.240 & 0.298 & 0.261 & 0.191 & 0.216 & 0.253 & 0.258 & 0.233 & 0.254 & 0.155 & 0.111 & 0.259 & 0.208 \\
F-16 & 0.254 & 0.146 & 0.251 & 0.283 & 0.263 & 0.236 & 0.226 & 0.233 & 0.232 & 0.155 & 0.111 & 0.222 & 0.208 \\
Su-35 & 0.240 & 0.298 & 0.261 & 0.335 & 0.304 & 0.258 & 0.258 & 0.257 & 0.261 & 0.460 & 0.389 & 0.259 & 0.292 \\
Mig-35 & 0.266 & 0.257 & 0.228 & 0.191 & 0.216 & 0.253 & 0.258 & 0.276 & 0.254 & 0.230 & 0.389 & 0.259 & 0.292 \\
\hline
\end{tabular}

Step2. The weighted-normalized decision matrix

Since the weight values of attributes $\left[w_{1}, w_{2}, \ldots, w_{n}\right]$ acquired from the FUCOM method, the weighted-normalized values of each attribute are acquired from the following equation.

Table 9

$$
\hat{a}_{i j}=a_{i j}^{*} \cdot w_{j ;} \quad i=0,1, \ldots, m ; j=1, \ldots, n
$$

The normalized-weighted decision matrix

\begin{tabular}{|c|c|c|c|c|c|c|c|c|c|c|c|c|c|}
\hline Alternative & $\hat{C_{1}}$ & $\hat{C}_{2}$ & $\hat{C}_{3}$ & $\hat{C}_{4}$ & $\hat{C}_{5}$ & $\hat{C}_{6}$ & $\hat{C}_{7}$ & $\hat{C}_{8}$ & $\hat{C}_{9}$ & $\hat{C}_{10}$ & $\hat{C}_{11}$ & $\hat{C}_{12}$ & $\hat{C}_{13}$ \\
\hline Ao & 0.046 & 0.052 & 0.051 & 0.035 & 0.044 & 0.056 & 0.039 & 0.040 & 0.047 & 0.032 & 0.018 & 0.049 & 0.035 \\
\hline F-16 & 0.048 & 0.025 & 0.049 & 0.052 & 0.054 & 0.052 & 0.034 & 0.040 & 0.043 & 0.032 & 0.018 & 0.042 & 0.035 \\
\hline Su-35 & 0.046 & 0.052 & 0.051 & 0.061 & 0.062 & 0.057 & 0.039 & 0.044 & 0.048 & 0.096 & 0.062 & 0.049 & 0.049 \\
\hline Mig-35 & 0.051 & 0.045 & 0.045 & 0.035 & 0.044 & 0.056 & 0.039 & 0.047 & 0.047 & 0.048 & 0.062 & 0.049 & 0.049 \\
\hline
\end{tabular}

Step3. The optimality function

The optimality function is calculated through the following equation for the $i$ th alternative. If the value $K_{i}$ is larger, it is better.

$$
\begin{aligned}
& K_{i}=\sum_{j=1}^{n} \hat{a}_{i j} ; \quad i=0,1, \ldots, m \\
& K_{o=} 0.544 ; K_{F 16}=0.525 ; K_{\text {Su35 }}=0.717 ; K_{\text {Mig35 }}=0.617
\end{aligned}
$$

\section{Step4. The Utility Degree}

We use the utility degree for the final ranking of alternatives. The utility degree is in the interval $[0,1]$. The utility degree $B_{\mathrm{i}}$ for the $i$ th alternative is attained from the following equation:

$$
B_{i}=\frac{K_{i}}{V_{0}} ; \quad i=0,1, \ldots, m
$$

The result, given the value $V_{0}$ equals 0.717 , for each alternative is as follows:

$$
B_{1=} 0.732, \quad B_{2}=1, \quad B_{3=} 0.859 .
$$

The final ranking of alternatives is presented in Table 10 .

Table 10

The final ranking of alternatives

\begin{tabular}{ccc}
\hline Alternatives & Utility Degree & Ranking \\
\hline F-16 & 0.732 & 3 \\
\hline
\end{tabular}




\begin{tabular}{ccc}
\hline Su-35 & 1 \\
Mig-35 & 0.859 & 1 \\
\hline
\end{tabular}

The alternative evaluation results are illustrated in Table 10 and indicate that the Su-35 is the optimal fighter aircraft for the VPAF. This assessment is based on the technical characteristics, economic constraints, and real conditions in Vietnam. Although the F-16 was better evaluated technically, surprisingly, it ranked third because of technical characteristics, cooperation, and synchronic system factors. This table presents a clear view of the most suitable option derived in this study.

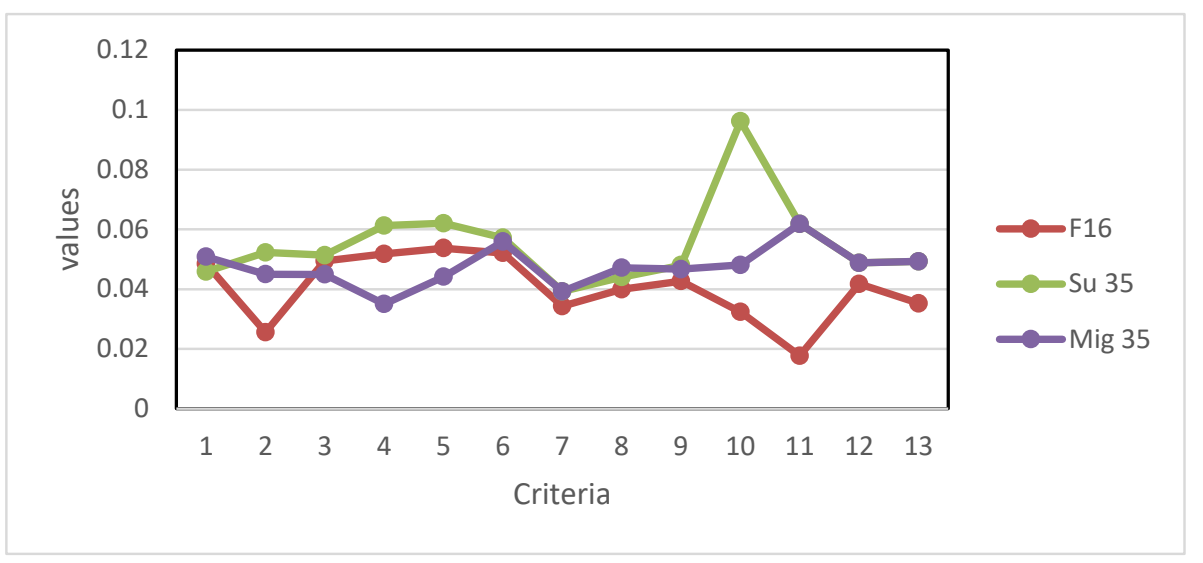

Fig. 1. Alternatives performance comparison

\section{Discussion and sensitivity analysis}

Defence purchases are strategically important for any country and depend on the conditions of the country and the defence strategy. Especially, procurement or development of aircraft requires huge defence budgetary expenditures, thereby necessitating careful assessment and selection of the appropriate aircraft. In the context of the economic and geopolitical challenges related to defence procurement, the trade-off between the requirements and constraints needs to be managed to ensure optimal selection. The selection of fighter aircrafts for the VPAF was considered in this study. Various aspects of a fighter aircraft purchase were evaluated by examining the financial status, strategic relationship, and technical characteristics as criteria. Using the ARAS-FUCOM approach for fighter aircraft selection, results showed that the Su-35 aircraft was the best solution, followed closely by the Mig-35 aircraft. Although the F-16 is technologically superior to both the Su-35 and Mig-35, the Su-35 and Mig-35 outweigh the F-16 in technical characteristics. Therefore, the Su-35 aircraft could be considered the most appropriate aircraft. To validate the robustness of the proposed framework, a sensitivity analysis was conducted and the result was compared with the weighted product (WP) method, which is another widely used MCDM method to connote the effect on the evaluation process and ranking of the solutions for fighter aircraft selection. The results of the sensitivity analysis are presented in Table 11.

Table 11

The result of sensitivity analysis ARAS and WP method

\begin{tabular}{cccc}
\hline Alternatives & ARAS & Weighted Product & Ranking \\
\hline F-16 & 0.525 & 0.239 & 3 \\
Su-35 & 0.717 & 0.397 & 1 \\
Mig-35 & 0.617 & 0.365 & 2 \\
\hline
\end{tabular}

The given result shows that all alternatives comply with ARAS, and WP have the same rank. That is, the Su-35 is ranked first, the Mig-35 ranked second, and the F-16 ranked third.

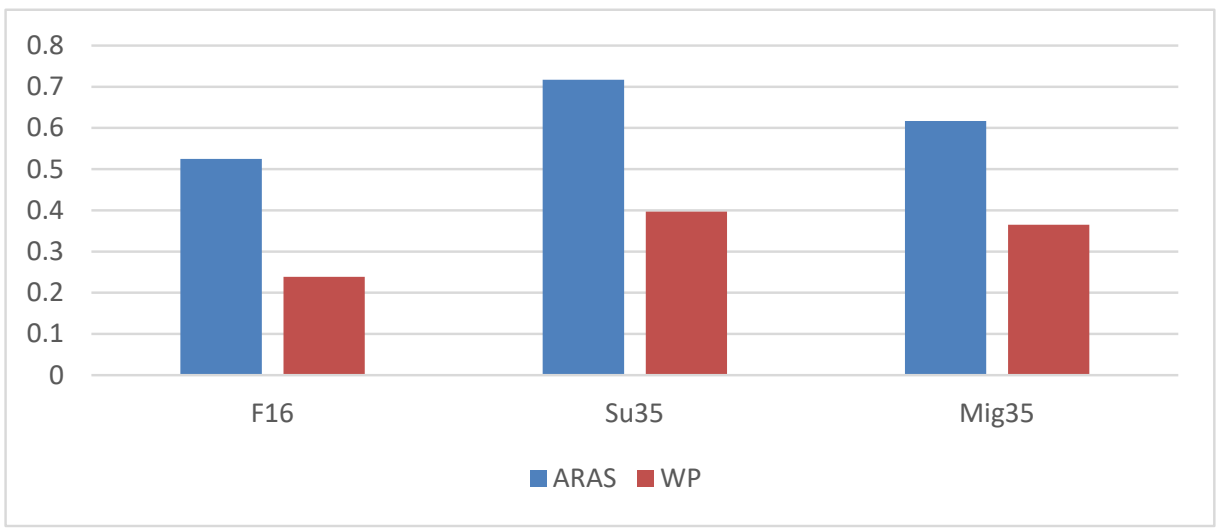




\section{Conclusion}

Fig. 2. Comparing the result of ARAS and WP

In this study, a combined ARAS-FUCOM method was employed to determine the best fighter aircraft among a set of alternatives for VPAF. FUCOM method has advantages over other techniques such as AHP and BWM, because it requires a lesser number of pairwise comparisons, and the result obtained is more consistent. The expert team determined thirteen criteria to evaluate aircraft, and FUCOM method was used throughout as decision-making process to acquire the final weight values of the criteria, while the ARAS method was used to derive the final ranking of fighter aircrafts with respect to criteria. Sensitivity analysis was conducted and the result was compared with the WP method to encorse the robustness of the proposed method. It was demonstrated that the proposed method privided reliable results. As a given result of the process, the Su-35 was the best suitable solution, followed closely by Mig-35. Although the F-16 outweighs in both acquisition and operational cost, the Su-35 ranks higher than both the Mig-35 and F-16 in some technical parameters. Therefore, the Su-35 could be considered a more suitable fighter aircraft, as it meets the technical requirements, cooperation strategic, and real-world VPAF conditions. This study can be considered as a reference for future studies on determining the efficiency of the fighter selection model.

\section{References}

Ali, Y., Asghar, A., Muhammad, N., \& Salman, A. (2017). Selection of a fighter aircraft to improve the effectiveness of air combat in the war on terror: Pakistan Air Force-a case in point. International Journal of the Analytic Hierarchy Process, 9(2).

Badi, I., \& Abdulshahed, A. (2019). Ranking the Libyan airlines by using full consistency method (FUCOM) and analytical hierarchy process (AHP). Operational Research in Engineering Sciences: Theory and Applications, 2(1), 1-14.

Cao, Q., Esangbedo, M. O., Bai, S., \& Esangbedo, C. O. (2019). Grey SWARA-FUCOM Weighting Method for Contractor Selection MCDM Problem: A Case Study of Floating Solar Panel Energy System Installation. Energies, $12(13), 2481$.

Dožić, S., \& Kalić, M. (2015). Comparison of two MCDM methodologies in aircraft type selection problem. Transportation Research Procedia, 10, 910-919.

Dožić, S., \& Kalić, M. (2016). Aircraft type selection problem: Application of different MCDM methods. In Advanced Concepts, Methodologies and Technologies for Transportation and Logistics (pp. 156-175). Springer, Cham.

Durmić, E. (2019). Evaluation of criteria for sustainable supplier selection using FUCOM method. Operational Research in Engineering Sciences: Theory and Applications, 2(1), 91-107.

Fazlollahtabar, H., Smailbašić, A., \& Stević, Ž. (2019). FUCOM method in group decision-making: Selection of forklift in a warehouse. Decision Making: Applications in Management and Engineering, 2(1), 49-65.

Karabašević, D., Paunkovic, J., \& Stanujkić, D. (2016). Ranking of companies according to the indicators of corporate social responsibility based on SWARA and ARAS methods. Serbian Journal of Management, 11(1), 43-53.

KİRACI, K., \& BAKIR, M. (2018). Application of commercial aircraft selection in aviation industry through multi-criteria decision making methods. Manisa Celal Bayar Üniversitesi Sosyal Bilimler Dergisi, 16(4), 307-332.

Pamučar, D., Stević, Ž., \& Sremac, S. (2018). A new model for determining weight coefficients of criteria in mcdm models: Full consistency method (fucom). Symmetry, 10(9), 393.

Paul, S., Bose, S., Singha, J., Pramanik, D., Midya, R., \& Haldar, A. (2017). Fighter aircraft selection using TOPSIS method. National Conference on Recent Trends in Information Technology \& Management.

Sofuoğlu, M. A. (2020). Fuzzy applications of FUCOM method in manufacturing environment. Politeknik Dergisi, 23(1), 189-195.

Stanujkic, D., Djordjevic, B., \& Karabasevic, D. (2015). Selection of candidates in the process of recruitment and selection of personnel based on the SWARA and ARAS methods. Quaestus Multidisciplinary Research Journal, 7, 53-64.

Wang, T. C., \& Chang, T. H. (2007). Application of TOPSIS in evaluating initial training aircraft under a fuzzy environment. Expert Systems with Applications, 33(4), 870-880.

Zavadskas, E. K., \& Turskis, Z. (2010). A new additive ratio assessment (ARAS) method in multicriteria decision-making. Technological and Economic Development of Economy, 16(2), 159-172.

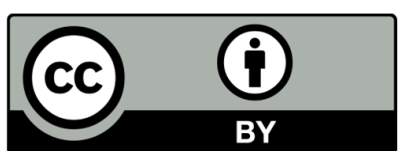

(C) 2020 by the authors; licensee Growing Science, Canada. This is an open access article distributed under the terms and conditions of the Creative Commons Attribution (CC-BY) license (http://creativecommons.org/licenses/by/4.0/). 